\title{
LONG -TERM MECHANICAL PROPERTIES OF HIGH STRENGTH SILICA FUME MORTAR USING ACCELERATED AGEING
}

\author{
H. S. Khalil, S. A. Ahmad, and E. M. Abdin, S. E. Zakey \\ Materials Engineering Department, Faculty of Engineering, \\ Zagazig University, Zagazig, Egypt
}

\begin{abstract}
This paper presents the experimental results of the long-term mechanical properties of silica fume high strength mortar (SFHSM). Nine mixes were carried out in this study; one mix without S.F used as a reference, four mixes with S.F used as a partial replacement and four mixes with S.F used as an addition. The S.F percentage ratios used were 5, 10, 15, and $20 \%$ of the cement weight. In all mixes the water/cementitious materials ratio was kept constant at 0.40 and the sand : cementations materials ratio was $3: 1$. The long-term properties were obtained by using the accelerated ageing procedure. The accelerated long-term specimens were cured in $100 \%$ relative humidity at room temperature for 28 days then in $60 \mathrm{oC}$ hot water till tested at $10,30,50,70,100$, and 120 days. This regime was used earlier in the literature on Glass fiber reinforced concrete (GRC) and it was found that it was equivalent to 1, 3, 5, 7, 10, and 12 years, respectively, of its exposure to natural weathering in Egypt. The experimental results showed a slight gradual increase in the compressive strength, indirect tensile strength, and flexural strength of SFHSM on the longterm as compared to the short-term results followed by a small reduction in the strengths after a certain age. S.F mortar specimens having $10 \%$ S.F as a partial replacement of cement weight showed about 9, 22, $16 \%$ increases in the compressive, indirect-tensile, and flexural strengths, respectively, of those of 56 days strengths after 70 days immersion in hot water, followed by a small reduction of about 8,6 , and $5 \%$ in the compressive, indirect-tensile, and flexural strengths, respectively, at 120 days in hot water.

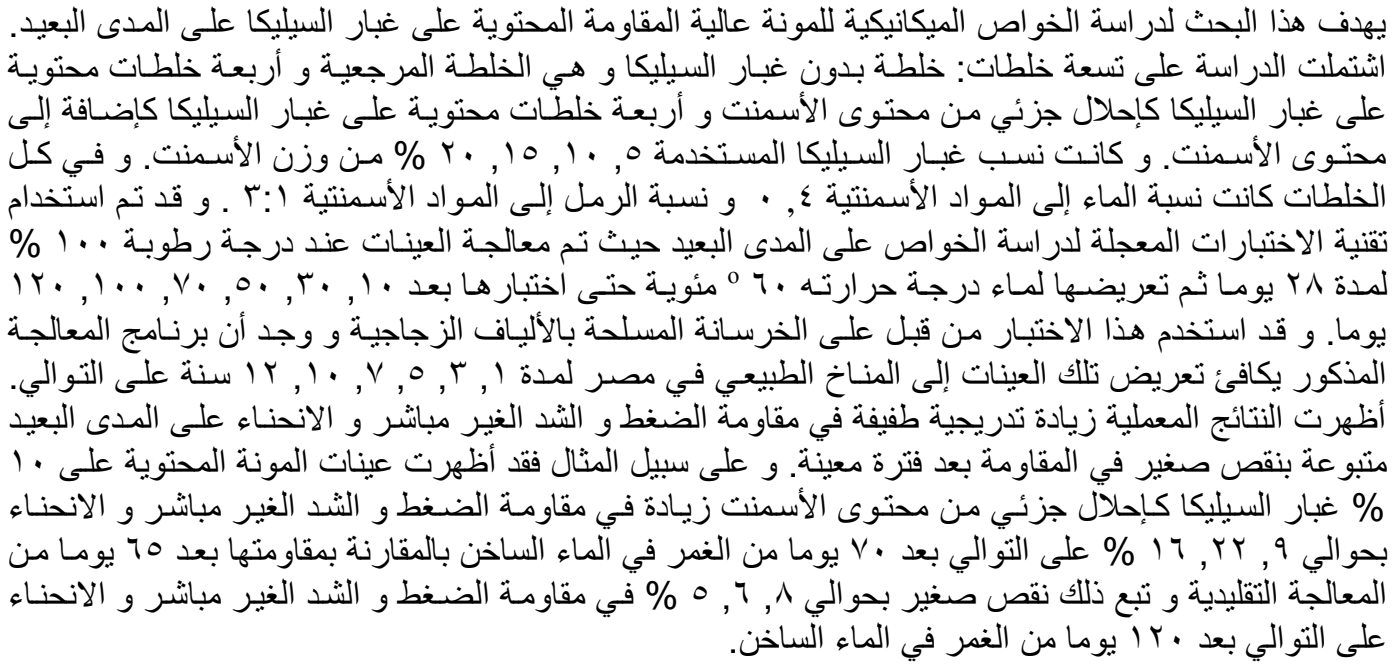

Keywords: Mortar specimens; silica fume; mechanical properties; long term; accelerated ageing

\section{INTRODUCTION}

Silica fume concrete (SFC) is a relatively new material which has achieved widespread use in the construction industry. Use of a new civil engineering material requires one to know its long-term behavior, or failing this, to have a reliable way of predicting it, at least for the anticipated life of the structure. The long - term strength may be obtained from exposure test samples to real working conditions over the expected working lifetimes, or estimated from the behavior of samples exposed to much more aggressive accelerated ageing conditions over shorter time periods.

Under real working conditions Gjørv [1] tested Ordinary Portland cement concrete (OPCC) specimens immersed in seawater for about 30 years in Trondhiem, Norway, he reported that, in general, compressive and flexural strengths in concrete made with OPC showed strength retrogressions after about 
5 years of immersion. Also 50 years properties of OPCC were tested by Washa et. al. [2], the authors found that the compressive strength of concrete cylinders generally increased as the logarithm of the age increased for about 10 years. After 10 years the compressive strength decreased or remained essentially the same, the modulus of rupture was approximately one-tenth of the compressive strength.

For silica fume high strength concrete (SFHSC) Carette [3] found significant strength loss in the compressive strength up to more that $20 \%$ between 3 months and 2 years in SFC cured in air while comparable concrete without S.F cured under the same conditions showed continued strength gain. Kurdi and Koury [4] tested two groups of mixes; the first group was silica fume normal strength concrete (SFNSC), which contained a control mix (without S.F) and five mixes with 5, 10, 15, 20, and $25 \%$ S.F with $\mathrm{W} /(\mathrm{C}+\mathrm{S} . \mathrm{F})$ of 0.60 . The second group was SFHSC, which contained a control mix and five mixes with 5, 10, 15, 20, and $25 \%$ S.F and $\mathrm{W} /(\mathrm{C}+\mathrm{S} . \mathrm{F})$ of 0.35 . The results showed a non negligible drop in strengths of all OPCC and SFHSC between the ages of 180 days and 3 years; except for concretes containing 5\% S.F normal strength and high strength concretes.

The long-term effects (3 years) of S.F, at concentrations up to $25 \%$ of the cement weight were studied on the compressive and flexural strengths of concretes cured in water and in air. The W/C ratio was varied between 0.38 and 1.32 . The compressive strength of concrete cured in water showed a continuous increase with age, while slight differences - positive or negative - were observed between 1 year and 3 years in compressive and flexural strengths of concrete cured in air [5]. Sasatani et. al. [6] studied SFHSC compressive strength among other concrete mixes in four different environments for five years. The four environments were as follows: A- in water at $20^{\circ} \mathrm{C}$ (wet condition), B- in air at $20^{\circ} \mathrm{C}$ and $60 \% \mathrm{RH}$ (dry condition indoor), C- on the roof of a building in Kanazawa University (repeated wet and dry conditions, outdoor), and Don the tidal zone at Matsuto beach facing the sea of Japan (repeated wet and dry conditions, marine environment). They found that $10 \%$ S.F concrete showed some reduction in compressive strength with exposure time when they were initially cured in water for 7 days and then continuously air-cured indoor for a long period. On the other hand the longterm behavior of SFC was studied for 10 years using cubes $100 \times 100 \times 100 \mathrm{~mm}$ dimensions. The test specimens were cured in water at $20^{\circ} \mathrm{C}$ or in air at $20^{\circ} \mathrm{C}$ and $50 \% \mathrm{RH}$. It was specified that the same procedures and the same apparatus were used for all tests. The compressive strength of the specimens cured in water increased continually with time, together with that of most of the specimens cured in air. The gains of strength observed were however less than in the case of curing in water. In the case of some SFC cured in air, a slight loss of compressive strength was deserved at 3 years, which disappeared at 10 years [5]. Aitcin and Laplante [7] indicated no tendency for long-term (4-6 years) strength loss in SFC. Also, Lachemi et al. [8] tested a sidewalk at Skw Canada. After 16 years they found that the concrete containing S.F have shown a better longterm behavior than the plain concrete without S.F that was used to construct a small part of the sidewalk. El-Aiat et. al. [9] tested HSC specimens at ages of 28, 360, 540 and 720 days. The S.F was used as an addition of $10 \%$ by weight of cement. The test results showed that the compressive, tensile and flexural strengths generally increase, with higher early age strength and higher early rate of strength gain, with time up to about two years.

Judgment on the adequacy of concrete is needed on the construction site much sooner than 28 days or even 7 days. There have been many attempts for the meaningful early determination of the strength potential of concrete [10]. The use of external heat sources for accelerated determination of control strengths began more than 60 years ago. Since then a wide variety of accelerated test methods have been recommended by various investigators. The highest temperature to be applied is usually that of a boiling water bath. When lower temperatures are used, the curing ambience is water or steam, although dry hot air has also been used with sealed molds [11]. Sabir [12] studied the influence of S.F on the strength development of concrete with S.F content in the range of $12-28 \%$. Results were given for compressive strengths up to 91 days for two water curing temperatures $20^{\circ} \mathrm{C}$ and $50^{\circ} \mathrm{C}$. He found that at higher temperatures of curing $\left(50^{\circ} \mathrm{C}\right)$ a higher compressive strength was obtained at early ages, but this trend was reversed with increasing age. For high-strength concrete when cured at $20^{\circ} \mathrm{C}$ it was shown that up to $16 \%$ S.F the reduction caused by the higher temperature was of the order of $4-10 \%$. Beyond $16 \%$ S.F content, however, the higher temperature caused an increase in the 28-day compressive strength of about $8-17 \%$. Curing at temperatures below $20^{\circ} \mathrm{C}$ retarded strength development more in case of SFC than in case of control concrete. S.F makes it possible to design low-heat concrete over a wide range of strength levels. Therefore, S.F is more sensitive to curing temperature than OPC [13]. But on the other hand, Yamoto et. al. [14] reported that when concrete was cured at $10^{\circ} \mathrm{C}$, the presence of silica fume did not essentially improve the strength of concrete at 7 days; however, it did at both 28 and 91 days. With higher curing temperature of 20,30 and $65^{\circ} \mathrm{C}$, the presence of silica fume substantially improved the 7 - 
day strength, as well as strengths after longer curing periods.

The accelerated ageing method is based on an assumption that measuring mechanical properties after storing specimens in water at elevated temperatures for short times may serve for predicting the mechanical properties of the material after long time of natural weathering. Early work at Building Research Establishment (U.K) had indicated that Glass fiber reinforced concrete (GRC) composites lost strength more rapidly when immersed in hot water. Litherland et. al. [15] tested GRC and the results of tests on the composites stored in artificial accelerated ageing conditions showed a consistent pattern of falling strength followed by a stable strength region. Composite strength changes in a variety of real climates showed similar patterns of behavior in initial falling strength region, with the same activation energy and a temperature dependence as the accelerated tests. Good correspondence was observed between predicted behavior and actual weathering over 10 years in the UK; a correlation of data under accelerated ageing and under natural weathering was obtained. Such Correlation has been made for the UK climate in which 1 day of storage in water at $60 \mathrm{oC}$ was equivalent to 272 days of natural weathering. Aindow et. al. [16] recently, however, showed that additional results have become available from materials exposed over a number of years in warmer climates, where changes occur significantly more quickly. For the purposes of comparison, the data from these hot sites has been treated as if it were accelerated ageing data in relation to the cooler UK climate. It has been transposed to the appropriate age in the UK weather using the acceleration factors given in Table (1), which were calculated from the mean annual temperature of the site. Based on the above discussion, and on the information obtained from the Egyptian Meteorological Authority (Cairo Airport Meteorological station) that the mean annual temperature in Cairo is about $26.5 \mathrm{oC}$ the acceleration factor of Egypt related to the UK is around 7.5. Hence, it could be said for GRC that one day of storage in water at $60 \mathrm{oC}$ is equivalent to 36.5 days of natural weathering in Egypt [17].

In this research work, the mechanical properties of SFHSM on the short-term and the optimum ratio of S.F content were studied and presented in an earlier work $[18,19]$. Here, the experimental results of the accelerated long-term mechanical properties of SFHSM are presented and discussed. The long-term specimens were cured in $100 \%$ relative humidity at room temperature for 28 days then in $60 \mathrm{oC}$ hot water till tested at 10, 30, 50, 70, 100, and 120 days. This regime used earlier in the literature on GRC was found to be equivalent to $1,3,5,7,10$, and 12 years, respectively, of its exposure to natural weathering in Egypt $[15,16,17]$. Compressive, indirect tensile, and flexural strength tests were performed on the cubic, cylindrical, and prismatic long - term specimens, respectively.

\section{EXPERIMENTAL INVESTIGATION}

Ordinary Portland cement (OPC) produced by the Suez company and meeting the requirements of ESS 373/1991 was used. Its fineness in terms of specific surface area was $3120 \mathrm{~cm}^{2} / \mathrm{gm}$ and its initial and final setting times were 100 minutes and 5.0 hours, respectively. Natural siliceous sand was used with a fineness modulus of 2.7 , bulk density of 1.67 ton $/ \mathrm{m}^{3}$, and specific gravity of 2.55 . Clean tap water without special taste, smell, color or turbidity was used. The silica fume was brought from factories of the Egyptian ferroalloys company located in Edfou, Egypt, with light gray color, specific surface area of $15.2 \times 10^{4} \mathrm{~cm}^{2} / \mathrm{gm}$, bulk density of $355 \mathrm{~kg} / \mathrm{m}^{3}$, and specific gravity of 2.15 . To keep the slump constant for all mixes; the high range water reducer (HRWR), Addicrete BVF1, was used.

The work reported here involves one reference mix without silica fume and eight mixes with silica fume (Table2). The silica fume was used as a partial replacement and as an addition to the cement content; its percentages were $5,10,15$ and $20 \%$ of the cement weight. The sand to cementitious materials $(\mathrm{OPC}+\mathrm{S} . \mathrm{F})$ ratio was kept constant at 3:1 by weight. The water to cementitious materials (W/OPC+S.F) ratio was kept constant at 0.40 and HRWR dose was determined to obtain a constant slump flow of mortar of about $125 \mathrm{~mm}$ diameter.

Mixing was performed using a small rotary drum mixer with high efficiency. The mixing procedure consisted of mixing all dry materials till obtaining a homogeneous mix (about 90 seconds) and then half of gauging water was added gradually while the mixer was rotating and the mortar was mixed for 3 minutes. The admixture (Addicrete BVF1) was then added to the remaining water ( $1 / 2$ of the gauging water) and introduced over 30 seconds and the mortar was mixed for another 3 minutes to insure full mixing.

Three types of specimens were made: $50 \mathrm{~mm}$ cubes, $75 \times 150 \mathrm{~mm}$ cylinders and $50 \times 50 \times 250 \mathrm{~mm}$ prismatic beams. At least three specimens were prepared to be tested at each testing condition in order to get their average value.

After casting, the specimens were stored in the laboratory at room temperature for 24 hours, and then they were removed from the molds. The specimens were cured in $100 \%$ relative humidity at room temperature for 28 days then in $60^{\circ} \mathrm{C}$ hot water till tested at 10, 30, 50, 70, 100 and 120 days. For the purpose of accelerated ageing, a special curing tank 
was made. The tank dimensions were 100x100x80 $\mathrm{cm}$ with a heater of $2000 \mathrm{Watt}$ power. The heater was fixed in the tank bottom center to allow good distribution of heat. The tank body was made of galvanized mild steel, and its boundaries were isolated with glass wool. The tank was put in a wooden box with a top cover, and a thermostat was used to control the water heat in the tank at the required temperature.

Finally, compressive, indirect tensile, and flexural strength tests were performed on the cubic, cylindrical, and prismatic long - term specimens, respectively

\section{RESULTS AND DISCUSSION}

\subsection{Compressive Strength}

Replacement case: Table (3) and Fig. (1-a) show the average results of the compressive strength test of plain mortar specimens and specimens containing S.F with percentage ratios of 5, 10, 15 and 20 as a partial replacement of the cement weight (N, R5, R10, R15, and R20, respectively). Results of the compressive strength were calculated in $\mathrm{N} / \mathrm{mm}^{2}$ and as a percentage of the corresponding reference mix result. The age of the test specimens was given in terms of the duration of immersion of the test specimens in hot water at $60^{\circ} \mathrm{C}$. The first point in each curve in the figure represents the short-term compressive strength and represented by the value of the compressive strength of the test specimens of the respective mix at 56 days for comparison purposes.

It can be seen that plain mortar specimens showed a slight gradual increase in the compressive strength on the accelerated long-term condition as compared to the short-term compressive strength at 56 days. This slight increase reached about $15 \%$ of that of the 56 days strength after 100 days immersion in hot water at $60^{\circ} \mathrm{C}$, after which a smaller reduction in compressive strength occurred of about $5 \%$ of that of the 56 days strength at 120 days of immersion in hot water.

With regard to the performance of SFHSM specimens, a similar trend of results to that of the plain mortar specimens was obtained; only a slight gradual increase in the compressive strength was obtained when compared to the 56 days strength of the respective S.F mix up to a certain duration period in the hot water, after which a slight reduction in the strength occurred. For example, the mix of 5\% S.F partial replacement (R5) showed an increase in the compressive strength of about $5 \%$ of that of the 56 days strength after 70 days of immersion in the hot water; after which a smaller reduction in the compressive strength occurred of about $4 \%$ of that of the 56 days strength at 120 days of immersion in the hot water.
The corresponding values for the mix of $15 \%$ S.F partial replacement (R15) were about $15 \%$ increase in the compressive strength of that of the 56 days strength after 70 days of immersion in the hot water; followed by a reduction in the strength of about $3 \%$ at 120 days of immersion in the hot water. The reduction in the compressive strength of the accelerated ageing specimens may be related to the carbonation effect: the decrease of the strength of mortar specimens after a long time may be due to the effect of carbon dioxide $\left(\mathrm{CO}_{2}\right)$ on the hydrated products of cement. The $\mathrm{CO}_{2}$ can decompose calcium silicate hydrate (C-S-H). This gives calcium carbonate $\left(\mathrm{CaCO}_{3}\right)$, which has a low strength in comparison with the C-S-H products; and silica gel which has swelling properties and no binding characteristics, thus, the strength of mortar decreases. Also, the $\mathrm{CO}_{2}$ can react with the calcium hydroxide $\left(\mathrm{Ca}(\mathrm{OH})_{2}\right)$ librated from the hydration of the Portland cement. Another possible reason for such reduction in the strength after a long time may be due to the following: it has also become apparent that microsilica is typically incompletely dispersed, so that the formation of agglomerates causes the mean particle size to be in the range $1-50 \mu \mathrm{m}$, rather than the 0.1 $0.2 \mu \mathrm{m}$ range frequently cited [20]. Exceptionally course agglomerations of micro-silica have the potential to behave as alkali-silica reactive aggregate particles and examples of resultant damage to concrete have been reported [21].

However the gain of strength due to the presence of S.F, which was obtained in the short-term interval, was also reflected in the results of the accelerated long-term interval.

Addition case: Table (3) and Fig. (1-b) show the average results of compressive test on the accelerated long-term condition of plain mortar specimens and specimens containing S.F with percentage ratios of 5 , 10,15 , and 20 as an addition to cement content (A5, $\mathrm{A} 10, \mathrm{~A} 15$, and A20, respectively). Results of the compressive strength were calculated in $N / \mathrm{mm}^{2}$ and as a percentage of the corresponding reference mix result. It can be seen clearly that the results here for the addition case are similar to those of the replacement case showing a slight gradual increase in the compressive strength on the accelerated longterm condition as compared to the short-term strength followed by a smaller reduction in the strength after a certain age.

As a comparison between the results of compressive strength of specimens containing S.F as a replacement and as an addition of cement weight; First and on the short-term at 56 days [21], it can be noted that the compressive strengths of specimens containing S.F as a replacement were little higher than the compressive strength of specimens containing S.F as an addition at the same ratios. For 
the first while one can expect that specimens containing S.F as an addition would give compressive strength results higher than specimens containing the same ratios of S.F as a replacement in contrast to the results obtained here. However, the results obtained can be explained as follows: mixes containing S.F as an addition had the same water/cementitious ratio and also the same sand/cementitious ratio as the control mix and mixes containing S.F as a replacement, which means that in these mixes small amounts of water and sand were also added to keep these ratios the same (Table2). This means that comparing between a mix with $10 \%$ S.F as an addition, for example, and a mix with $10 \%$ S.F as a replacement shows that the first one had an increase in the amounts of all its ingredients except S.F when compared to the second mix, which means that the first had a smaller S.F/C ratio than the other, and as a result, it would be expected to have a lower strength than that of the second mix and this was the result obtained (Table 3 and Fig. 1).

Second and on the long-term, it can be noted that the results of the mixes of the same percentage of S.F content as replacement or addition were close to each other and having the same trend of results on the accelerated long-term. This confirms the behavior of the SFHSM mixes on the accelerated long-term deduced from the test results, for example see Fig. (2).

It is worth here at the end of this portion of analysis of results on the accelerated long-term behavior of SFHSM specimens under compression to mention that high strength concrete is usually designed for the 56 days compressive strength and the additional strength gained with time on the longterm run as a result of the continuation of the chemical reaction at a quite lower rate of reaction is considered as a margin of safety.

\subsection{Indirect Tensile Strength}

Replacement case: Table (4) and Fig. (3-a) show the average results of the indirect tensile strength test of plain mortar specimens and specimens containing S.F with percentage ratios of 5 , 10,15 and 20 as a partial replacement of cement weight (N, R5, R10, R15, and R20). As shown the plain mortar specimens showed a little gradual increase in the indirect tensile (splitting) strength with time on the accelerated long-term interval as compared to the short-term indirect tensile strength at 56 days. This increase reached about $21 \%$ of that of the 56 days strength after 100 days of curing in hot water. But at 120 days of curing, the indirect tensile strength decreased by about $14 \%$ of that of the 56 days indirect tensile strength.
Also, the SFHSM specimens on the accelerated long-term showed a similar trend of results to that of the plain mortar specimens; a little gradual increase in the indirect tensile strength was recorded when compared to the 56 days indirect tensile strength of the respective S.F mix up to a certain age in hot water, then a little reduction in strength was occurred. For example, the mix of $5 \%$ S.F partial replacement (R5) showed an increase in the indirect tensile strength of about $18 \%$ of that of the 56 days strength after 100 days of curing in hot water, after which the indirect tensile strength remained nearly constant up to 120 days of curing in hot water. Also, in the case of the mix of $15 \%$ S.F partial replacement (R15) there was an increase in the indirect-tensile strength after 100 days in hot water for curing of about $28 \%$ of that of the 56 days strength, after which the indirect tensile strength remained nearly constant up to 120 days of curing in hot water.

Addition case: Table (4) and Fig. (3-b) show the average results of the indirect tensile test on the accelerated long-term of plain mortar specimens and specimens containing S.F as an addition to the cement content with percentage ratios 5, 10, 15 and 20 from the cement weight.

The gain of strength due to the presence of S.F, which was obtained in the short-term interval, was also reflected in the results of the accelerated longterm interval. For example, the mix of 5\% S.F addition (A5) showed an increase in the indirect tensile strength of about $20 \%$ of the 56 days strength after 50 days of curing. But after 120 days of curing a $9 \%$ reduction in the indirect tensile strength occurred. Also, for the $15 \%$ S.F addition mix (A15), an increase occurred in the indirect tensile strength of about $28 \%$ of the 56 days strength after 100 days of curing in hot water. But after 120 days of curing in hot water a $17 \%$ reduction in the indirect tensile strength occurred.

As a comparison between the results of the indirect tensile strength of specimens containing S.F with ratios 5, 10, 15 and $20 \%$ as replacement and addition cases, It can be seen from Table (4) that the indirect tensile strength of mixes of the same percentages of S.F content were so close to each other and having the same trend of results on the long-term (Fig. 5). This confirms the behavior of SFHSM on the long-term deduced from the test results.

It is worth here at the end of this portion of analysis of results on the accelerated long-term behavior of SFHSM specimens to mention that results of the indirect tensile strength were having the same trend of results as those of the compressive test specimens. 


\subsection{Flexural Strength}

Replacement case: The average results of the flexural strength test of plain mortar specimens and specimens containing S.F with partial replacement ratios of 5, 10, 15 and $20 \%(\mathrm{R} 5, \mathrm{R} 10, \mathrm{R} 15$ and $\mathrm{R} 20$, respectively) by cement weight are shown in Table (5) and Fig. (5-a). It can be seen that the plain mortar specimens showed a gradual increase in the flexural strength with time on the accelerated long-term interval compared to the short-term flexural strength at 56 days. This increase was about $23 \%$ of that of the 56 days short-term strength after 70 days of curing in $60^{\circ} \mathrm{C}$ hot water. But after 120 days of hot water curing about $17 \%$ reduction in the flexural strength occurred. Also, SFHSM specimens on the accelerated long-term followed the same trend of results of the plain mortar specimens; the flexural strength gradually increased with time on the longterm interval with respect to the 56 days flexural strength of the respective S.F mix till a certain age in hot water. For example, the mix of $5 \%$ S.F partial replacement (R5) of cement weight showed an increase in the flexural strength of about $27 \%$ of that of the 56 days strength after 70 days in hot water. But after 120 days of hot water curing about $2 \%$ reduction in the flexural strength occurred. Also the mix of $15 \%$ S.F partial replacement (R15) of cement weight showed an increase in the flexural strength of about $7 \%$ of that of 56 days short-term flexural strength after 50 days in hot water. But after 120 days in hot water about $16 \%$ reduction occurred. However, some of the mixes showed a reduction in the flexural strength after a certain age in hot water slightly less than the 56 day strength as shown in Table (5) and Fig. (5-a). The compression and indirect tension tests for those mixes did not show results on the accelerated long-term less than the 56 days strength. This contradiction could be cited in some results in the literature [21]. However another group of the tested mixes showed the same trend of results of the flexural strength as those of the compressive and indirect tensile strengths.

Therefore, the relatively higher reduction in the flexural strength on the accelerated long-term in comparison to the behavior under compression and splitting tension needs further investigation in future studies.

Addition case: Table (5) and Fig. (5-b) show the average flexural strength test results of plain mortar specimens and specimens containing 5, 10, 15 and $20 \%$ S.F addition ratios by cement weight (A5, A10, A15 and A20, respectively). The results showed that the flexural strength values of specimens contained S.F as an addition was improved with time on the accelerated long-term interval up to a certain age and then decreased. For example, at 5\% S.F addition ratio (A5), there was an increase in the flexural strength of about $3 \%$ of that of 56 days short-term flexural strength after 70 days of curing in hot water, but after 120 days of curing this increase was vanished. Also at $15 \%$ S.F addition mix (A15), there was an increase in the flexural strength of about $6 \%$ after 70 days of curing in hot water, but after 120 days of curing a reduction in the flexural strength occurred of about $15 \%$.

Table (5) shows a comparison between the results of the flexural strength of specimens containing S.F with ratios 5, 10, 15 and $20 \%$ as replacement and addition cases. However, it should be noted that the comparison between the results of specimens containing S.F as a replacement and those containing S.F as an addition was more clear in the case of the compressive and indirect splitting tensile strength than in the case of flexural strength, and this can be related to the nature of these tests and the accuracy obtained in each of them, see Fig. (6).

\section{CONCLUSIONS}

1- Plain mortar specimens showed slight gradual increase in the compressive, indirect tensile and flexural strengths on the long-term as compared to the short-term results followed by a small reduction in the strengths after a certain age.

2- Plain mortar specimens showed about 14\%, 15 , and $23 \%$ increases in the compressive strength, indirect-tensile, and flexural strengths, respectively, after 70 days of immersion in hot water at $60 \mathrm{oC}$ as compared to the corresponding 56 days strengths, and followed by a reduction of about 3, 8, and $17 \%$ in the compressive strength, indirect-tensile, and flexural strengths, respectively, after120 days of immersion in hot water.

3- Silica fume high strength mortar specimens showed the same trend on the accelerated long-term behavior as that of plain mortar specimens under compression, indirect tension and flexure tests.

4- S.F mortar specimens having $10 \%$ S.F as a partial replacement of cement weight showed about $9,22,16 \%$ increases in the compressive, indirecttensile, and flexural strengths, respectively of those of 56 days strengths after 70 days immersion in hot water, followed by a small reduction of about 8,6 , and $5 \%$ in the compressive, indirect-tensile, and flexural strengths, respectively, at 120 days in hot water.

5- S.F mortar specimens having $15 \%$ S.F as a partial replacement of cement weight showed about $15,22,1 \%$ increases in the compressive, indirecttensile, and flexural strengths, respectively of those of 56 days strengths after 70 days immersion in hot water, followed by a small reduction of about 3 , an increase of about $6 \%$, and a reduction of about $10 \%$ in the compressive, indirect-tensile, and flexural strengths, respectively, at 120 days in hot water. 
6- The reduction in strength obtained on the accelerated long-term may be due to the carbonation effect and also the tendency of some of the S.F to agglomerate and showing a potential for the alkalisilica reaction.

7- The gain in strength obtained on the accelerated long-term was considered a margin of safety as high strength concrete is usually designed for the 56 days compressive strength according to the standard codes of practice.

8- The behavior of SFHSM specimens on the accelerated long-term under flexure needs further investigation as not all the obtained results were in agreement with the trend of results of the compression and splitting tension test specimens.

\section{REFERENCES}

[1] Gjǿrv, Odd, E., "Long-Term Durability of Concrete in Seawater", ACI Material Journal, Proceedings Vol. 68, No. 1, 1971, PP. 60-67.

[2] Washa, G.W., Saemonn, J.C., and Cramer, S.M., "Fifty Years Properties of Concrete Made in 1937", ACI Material Journal, Vol. 86, No. 4, 1989, PP. 367-371.

[3] Carette, G.G., "Preliminary Data on Long-Term Strength Development of Condensed Silica Fume Concrete", $3^{\text {rd }}$ International Conference on Fly Ash, Silica Fume, Slag and Natural Pozzolans in Concrete, Trondheim, Supplementary Papers, 1989, PP. 597-617.

[4] Kurdi, A., and Koury. S., "Silica Fume Improves Concrete Strength; Is That True?", $3^{\text {rd }}$ Alexandria Conference on Structural and Geotechnical Eng. (ACSGES), Faculty of Eng., Alexandria University, 1997, PP. 109-127.

[5] Delarrard, F., and Bostvironnois, J.L., "On the Long-Term Strength Losses of Silica Fume High Strength Concretes", Magazine of Concrete Research, Vol. 43, No. 155, 1991, PP. 109-119.

[6] Sasatani, T., Torii, K., and Kowamura, M., "Five Years Exposure Test on Long-Term Properties of Concretes Containing Fly Ash, Blast Furnace Slag and Silica Fume", Fly Ash, Silica Fume, Slag and Natural Pozzolans in Concrete Proceedings, $5^{\text {th }} \quad$ International Conference, Milwaukee, Wisconsin, USA, Vol. 1, 1995, PP. 283-295.

[7] Aitcin, P.C., and Laplante, P., "Long-Term Compressive Strength of Silica Fume Concrete", Journal of Materials in Civil Engineering, Vol. 3, No. 3, 1990, PP. 164-170.

[8] Lachemi, M., Li, G., Tagnit-Humou, A., and Aitcin, P.C., "Long-Term Performance of Silica Fume Concrete", Concrete International, January, 1998, PP. 59-65.

[9] El-Aiat, M.M., Balaha, M.M., Anwar, H.E., Abedel-Rahman, A.G., "Long-Term Behavior of
Silica Fume Concrete Exposed to Different Aggressive Media", Engineering Research Journal, Vol. 28, No. 3, 2005, PP. 277-284.

[10] "Strength and Related Properties of Concrete: a Quantitative Approach", Sàndor Popvics, Wiley, New York, 1998, PP. 18-38

[11] http://www.astm.org/Standards/C684.htm, "Standard Test Method for Making, Accelerated Curing, and Testing Compressive Test Specimens", ASTM C684-99, 2003.

[12] Sabir, B.B., "High Strength Condensed Silica Fume Concrete", Magazine of Concrete Research, Vol. 47, No. 172, 1995, PP.219-226.

[13] Shah, S.P., Ahmad, S.H., "High Performance Concrete and Applications", Edwar Annold, London, 1994.

[14] Yamoto, T., Emoto, Y., and Soedo, M., "Strength and Freezing and Thawing Resistance of Concrete Incorporating Condensed Silica Fume", Proceedings, CANMET/ACI $2^{\text {nd }}$ International Conference on the Use of Fly Ash, Silica Fume, Slag, and Natural Pozzolans in Concrete, Madrid, V. M. Malhatra, Sp-91, Vol. 2, American Concrete Institute, Detroit, PP. 1095-1117.

[15]Litherland, K.L., Maguire, P., and Proctor, P.A., "The Use of Accelerated Ageing Procedures to Predict the Long-term Strength of GRC Composites", Cement and Concrete Research, Vol. 11, No. 3, 1981, PP. 455-466.

[16] Aindow, A.J., Oakly, D.R., and Proctor, B.A., "A Comparison of Weathering Behavior of GRC with Predictions Mode from Accelerated Ageing Testes", Cement and Concrete Research, Vol. 14, No. 2, 1984, PP. 271-274.

[17]Farahat, H.A., "Durability of Glass Fiber Reinforced Cement Mortar", M.Sc. Thesis, Faculty of Engineering, Ain Shams University, Cairo, Egypt, 2002.

[18]Zakey, S. E., "Short and Long - term Properties of Silica Fume High Strength Mortar", M. Sc. Thesis, Faculty of Engineering, Zagazig University, Zagazig, Egypt,2009.

[19] Khalil. H.S., Ahmad, S.A., Abdin, E.M., and Zakey, S.E., "Effect of Silica Fume on the Mechanical Properties of High Strength Mortar", The Egyptian International Journal of Engineering Science and Technology, Vol. 12, No. 2, 2009, PP. 181-193.

[20]St Jhon, D.A., Poole, A.B., and Sims, I., "Concrete Petrography", Hand Book of Investigative Techniques, London, Edward Arnold, 1997.

[21] Malhatra, V.M., Ramachandron, V.S. and Feldman, R.F., "Condensed Silica Fume in Concrete", CRC Press, Inc Baca, Raton, Florida, 1987. 
H.S. Khalil, S.A. Ahmad, E.M. Abdin, S.E. Zakey, "Long -Term Mechanical Properties of High Strength ... "

Table 1, Acceleration factors of various warm climate sites related to UK [16]

\begin{tabular}{|c|c|c|}
\hline Site & Mean annual temperature $\left({ }^{\mathbf{0}} \mathbf{C}\right)$ & Time equivalent to UK \\
\hline United Kingdom & 10.4 & 1 \\
\hline Arizona, US & 21.7 & 4.2 \\
\hline Lnnisfail, Australia & 23.6 & 5.5 \\
\hline Cloncurry, Australia & 26.2 & 7.3 \\
\hline Lagos, Nigeria & 26.7 & 7.8 \\
\hline Bombay, India & 27.6 & 8.4 \\
\hline
\end{tabular}

Table 2, Mix proportions of the mixes tested.

\begin{tabular}{|c|c|c|c|c|c|c|c|c|c|c|c|c|}
\hline \multirow[b]{2}{*}{$\begin{array}{c}\text { Mix } \\
\text { Symbol }\end{array}$} & \multirow[b]{2}{*}{ Mix type } & \multicolumn{5}{|c|}{ Ingredients } & \multicolumn{6}{|c|}{ \% Ratios } \\
\hline & & $\begin{array}{c}\text { Cement }(\mathrm{C}) \\
\mathrm{Kg}\end{array}$ & $\begin{array}{l}\text { S.F } \\
\mathrm{Kg}\end{array}$ & $\begin{array}{c}\text { Sand (S) } \\
\mathrm{Kg}\end{array}$ & $\begin{array}{l}\text { Water } \\
\text { (W) } \\
\text { Liter }\end{array}$ & $\begin{array}{c}\text { SUP }^{*} \\
\text { gm }\end{array}$ & $\frac{S . F}{C}$ & $\frac{W}{C}$ & $\frac{S}{C}$ & $\frac{W}{C+S . F}$ & $\frac{S}{c+S . F}$ & $\frac{\text { Sup }}{c+S . F}$ \\
\hline $\mathrm{N}$ & Normal mix & 31.00 & ----- & 92.90 & 12.40 & 528 & 0.00 & 40.00 & & 40 & 300 & 1.7 \\
\hline $\mathrm{R}_{5}$ & $5 \%$ Rep. & 29.45 & 1.55 & 92.90 & 12.40 & 600 & 5.26 & 42.10 & 300.00 & 40 & 300 & 1.9 \\
\hline $\mathrm{R}_{10}$ & $10 \%$ Rep. & 27.90 & 3.10 & 92.90 & 12.40 & 620 & 11.11 & 44.44 & 315.45 & 40 & 300 & 2.0 \\
\hline $\mathrm{R}_{15}$ & $15 \%$ Rep. & 26.45 & 4.65 & 92.90 & 12.40 & 660 & 17.58 & 46.88 & & 40 & 300 & 2.1 \\
\hline $\mathrm{R}_{20}$ & $20 \%$ Rep. & 24.90 & 6.20 & 92.90 & 12.40 & 680 & 24.90 & 49.80 & & 40 & 300 & 2.2 \\
\hline $\mathrm{A}_{5}$ & $5 \%$ Add. & 31.00 & 1.55 & 97.65 & 13.02 & 560 & 5.00 & 42.58 & 23000 & 40 & 300 & 1.7 \\
\hline $\mathrm{A}_{10}$ & $10 \%$ Add. & 31.00 & 3.10 & 102.30 & 13.64 & 570 & 10.00 & 44.00 & $\begin{array}{l}00330.00 \\
3450036\end{array}$ & 40 & 300 & 1.7 \\
\hline $\mathrm{A}_{15}$ & $15 \%$ Add. & 31.00 & 4.65 & 106.95 & 14.26 & 590 & 15.00 & 46.00 & $\begin{array}{l}+5.0036 \\
0.00\end{array}$ & 40 & 300 & 1.7 \\
\hline $\mathrm{A}_{20}$ & $20 \%$ Add. & 31.00 & 6.20 & 111.60 & 14.88 & 620 & 20.00 & 48.00 & & 40 & 300 & 1.7 \\
\hline
\end{tabular}

:Superplasticizer

Table 3, Results of the compressive strength test specimens in $\mathrm{N} / \mathrm{mm}^{2}$ and as a percentage of the corresponding reference result at durations in days of $60{ }^{\circ} \mathrm{C}$ hot water exposure

\begin{tabular}{|c|c|c|c|c|c|c|c|c|c|c|c|c|c|}
\hline \multicolumn{9}{|c|}{ Compressive strength, N/mm } & \multicolumn{4}{c|}{ \% compressive strength } \\
\hline $\begin{array}{c}56 \text { days } \\
\text { strengt } \\
\text { h }\end{array}$ & $\begin{array}{c}10 \\
\text { days }\end{array}$ & $\begin{array}{c}30 \\
\text { days }\end{array}$ & 50 days & 70 days & $\begin{array}{c}100 \\
\text { days }\end{array}$ & $\begin{array}{c}120 \\
\text { days }\end{array}$ & $\begin{array}{c}56 \text { days } \\
\text { strengt } \\
\text { h }\end{array}$ & $\begin{array}{c}10 \\
\text { days }\end{array}$ & 30 days & 50 days & 70 days & $\begin{array}{c}100 \\
\text { days }\end{array}$ & $\begin{array}{c}120 \\
\text { days }\end{array}$ \\
\hline 26.93 & 28.6 & 29.78 & 29.78 & 30.60 & 31.01 & 29.78 & 100 & 100 & 100 & 100 & 100 & 100 & 100 \\
\hline 43.66 & 44.27 & 44.88 & 45.29 & 45.98 & 44.88 & 44.06 & 162 & 155 & 151 & 152 & 150 & 145 & 148 \\
\hline 45.90 & 46.92 & 49.57 & 50.80 & 50.31 & 48.55 & 46.1 & 170 & 162 & 166 & 171 & 164 & 175 & 151 \\
\hline 48.67 & 48.80 & 50.78 & 52.92 & 56.10 & 54.79 & 54.67 & 181 & 171 & 168 & 178 & 183 & 176 & 184 \\
\hline 46.92 & 48.55 & 50.31 & 51.00 & 51.29 & 52.43 & 52.43 & 174 & 170 & 169 & 171 & 168 & 169 & 176 \\
\hline 42.84 & 44.06 & 45.98 & 46.51 & 46.63 & 48.18 & 46.51 & 159 & 154 & 154 & 156 & 152 & 155 & 156 \\
\hline 43.66 & 46.54 & 47.33 & 48.55 & 49.49 & 50.39 & 48.96 & 170 & 163 & 159 & 163 & 162 & 162 & 164 \\
\hline 44.06 & 46.92 & 47.94 & 51.00 & 51.80 & 51.00 & 48.96 & 164 & 164 & 161 & 171 & 169 & 164 & 163 \\
\hline 45.29 & 48.55 & 49.37 & 51.82 & 52.63 & 52.00 & 50.80 & 168 & 170 & 166 & 174 & 172 & 168 & 171 \\
\hline
\end{tabular}


H.S. Khalil, S.A. Ahmad, E.M. Abdin, S.E. Zakey, "Long -Term Mechanical Properties of High Strength ... "

Table 4, Results of the Indirect tensile (splitting) strength test specimens in N/mm ${ }^{2}$ and as a percentage of the corresponding reference result at durations in days of $60{ }^{\circ} \mathrm{C}$ hot water exposure

\begin{tabular}{|c|c|c|c|c|c|c|c|c|c|c|c|c|c|c|}
\hline \multirow[b]{2}{*}{$\begin{array}{c}\text { Mix } \\
\text { symbol }\end{array}$} & \multicolumn{7}{|c|}{ Indirect tensile (splitting) strength, $\mathrm{N} / \mathrm{mm}^{2}$} & \multicolumn{7}{|c|}{$\%$ Indirect tensile (splitting) strength } \\
\hline & $\begin{array}{l}6 \text { days } \\
\text { rength }\end{array}$ & $\begin{array}{c}10 \\
\text { days }\end{array}$ & $\begin{array}{c}30 \\
\text { days }\end{array}$ & $\begin{array}{c}50 \\
\text { days }\end{array}$ & $\begin{array}{c}70 \\
\text { days }\end{array}$ & $\begin{array}{c}100 \\
\text { days }\end{array}$ & $\begin{array}{c}120 \\
\text { days }\end{array}$ & & $\begin{array}{c}10 \\
\text { days }\end{array}$ & $\begin{array}{c}30 \\
\text { days }\end{array}$ & $\begin{array}{c}50 \\
\text { days }\end{array}$ & $\begin{array}{c}70 \\
\text { days }\end{array}$ & $\begin{array}{c}100 \\
\text { days }\end{array}$ & $\begin{array}{r}120 \\
\text { days }\end{array}$ \\
\hline $\mathrm{N}$ & & 366 & 383 & 3.92 & 4.02 & & & 100 & 100 & 100 & 100 & 100 & 100 & 100 \\
\hline R5 & & & & & & & & & 28 & 125 & 129 & 31 & & 145 \\
\hline $\mathrm{R} 10$ & & 5.21 & 540 & 577 & 6.03 & 6.29 & 5.65 & 141 & 142 & 143 & 147 & 150 & 9 & 151 \\
\hline $\mathrm{R} 15$ & & & & & 6.20 & 6.50 & 6.49 & 145 & 145 & 147 & 156 & 154 & 4 & 173 \\
\hline $\mathrm{R} 20$ & 4.78 & 5.01 & 5.23 & 5.71 & 6.06 & 6.55 & 6.29 & 137 & 137 & 137 & 146 & 151 & 155 & 167 \\
\hline A5 & & 4.62 & 4.79 & .99 & 4.96 & 4.73 & 4.62 & 119 & 126 & 125 & 137 & 123 & 112 & 123 \\
\hline A10 & 4.62 & 4.70 & 4.86 & 5.02 & 5.38 & 5.74 & 5.14 & 132 & 128 & 127 & 128 & 134 & 136 & 137 \\
\hline A15 & & 5.08 & 5.42 & 5.48 & 5.77 & 6.06 & 5.25 & 135 & 139 & 142 & 140 & 144 & 143 & 140 \\
\hline A20 & 4.83 & 4.96 & 5.31 & 5.44 & 5.41 & 5.91 & 5.34 & 138 & 136 & 139 & 139 & 135 & 140 & 142 \\
\hline
\end{tabular}

Table 5, Results of the Flexural strength test specimens in $\mathrm{N} / \mathrm{mm}^{2}$ and as a percentage of the corresponding reference result at durations in days of $60{ }^{\circ} \mathrm{C}$ hot water exposure

\begin{tabular}{|c|c|c|c|c|c|c|c|c|c|c|c|c|c|c|}
\hline \multirow[b]{2}{*}{$\begin{array}{c}\text { Mix } \\
\text { Symbol }\end{array}$} & \multicolumn{7}{|c|}{ Flexural strength, $\mathbf{N} / \mathrm{mm}^{2}$} & \multicolumn{7}{|c|}{$\% \quad$ Flexural strength } \\
\hline & $\begin{array}{l}56 \text { days } \\
\text { strength }\end{array}$ & $\begin{array}{c}10 \\
\text { days }\end{array}$ & $\begin{array}{c}30 \\
\text { days }\end{array}$ & $\begin{array}{c}50 \\
\text { days }\end{array}$ & $\begin{array}{c}70 \\
\text { days }\end{array}$ & $\begin{array}{c}100 \\
\text { days }\end{array}$ & $\begin{array}{c}120 \\
\text { days }\end{array}$ & $\begin{array}{l}56 \text { days } \\
\text { strength }\end{array}$ & $\begin{array}{c}10 \\
\text { days }\end{array}$ & $\begin{array}{c}30 \\
\text { days }\end{array}$ & $\begin{array}{c}50 \\
\text { days }\end{array}$ & $\begin{array}{c}70 \\
\text { days }\end{array}$ & $\begin{array}{l}100 \\
\text { days }\end{array}$ & $\begin{array}{r}120 \\
\text { days }\end{array}$ \\
\hline $\mathrm{N}$ & 5.75 & 5.75 & 6.85 & 6.85 & 7.1 & 6.61 & 6.12 & 100 & 100 & 100 & 100 & 100 & 100 & 100 \\
\hline $\mathrm{R} 5$ & 7.34 & 8.32 & 8.45 & 8.57 & 9.30 & 9.18 & 9.18 & 128 & 134 & 123 & 125 & 131 & 139 & 150 \\
\hline R10 & 8.45 & 8.57 & 9.55 & 10.16 & 9.79 & 9.55 & 9.30 & 148 & 140 & 139 & 148 & 138 & 144 & 152 \\
\hline R15 & 10.77 & 11.02 & 11.26 & 11.51 & 10.89 & 10.16 & 9.79 & 188 & 180 & 164 & 168 & 153 & 154 & 160 \\
\hline $\mathrm{R} 20$ & 9.42 & 9.42 & 9.55 & 9.79 & 9.30 & 9.18 & 9.18 & 158 & 154 & 139 & 143 & 131 & 139 & 150 \\
\hline A5 & 7.96 & 7.96 & 8.08 & 8.08 & 8.20 & 7.96 & 7.96 & 131 & 130 & 118 & 118 & 115 & 120 & 130 \\
\hline A10 & 10.28 & 10.77 & 11.26 & 11.02 & 10.65 & 9.91 & 9.42 & 179 & 176 & 164 & 161 & 150 & 150 & 154 \\
\hline A15 & 11.02 & 11.38 & 11.75 & 11.75 & 11.26 & 10.65 & 10.04 & 143 & 186 & 172 & 172 & 159 & 161 & 164 \\
\hline A20 & 11.02 & 11.26 & 11.51 & 11.51 & 11.02 & 10.28 & 9.79 & 193 & 184 & 168 & 168 & 155 & 156 & 160 \\
\hline
\end{tabular}


H.S. Khalil, S.A. Ahmad, E.M. Abdin, S.E. Zakey, "Long -Term Mechanical Properties of High Strength ... "

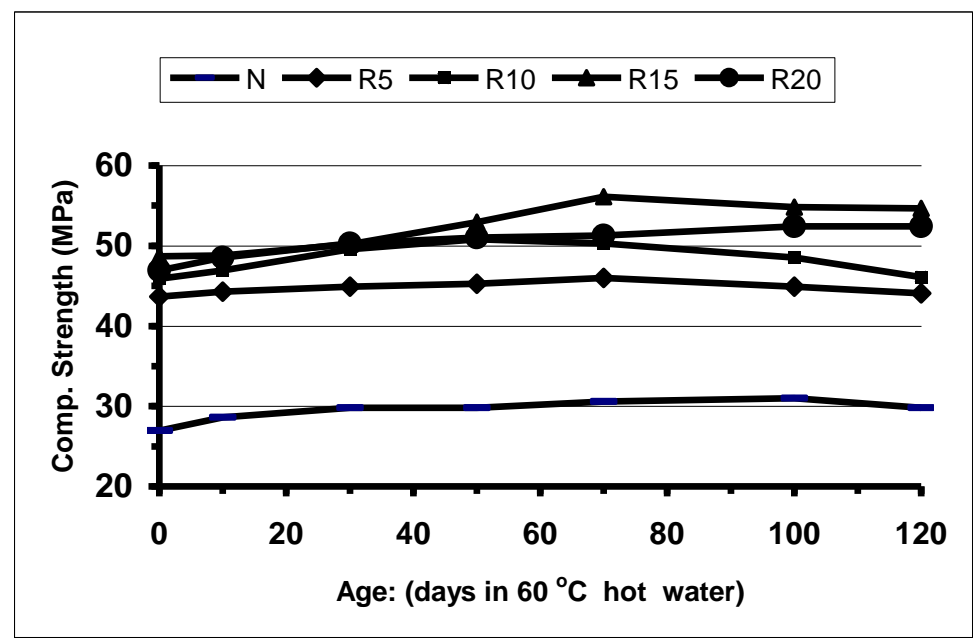

(a) S.F was used as a partial replacement

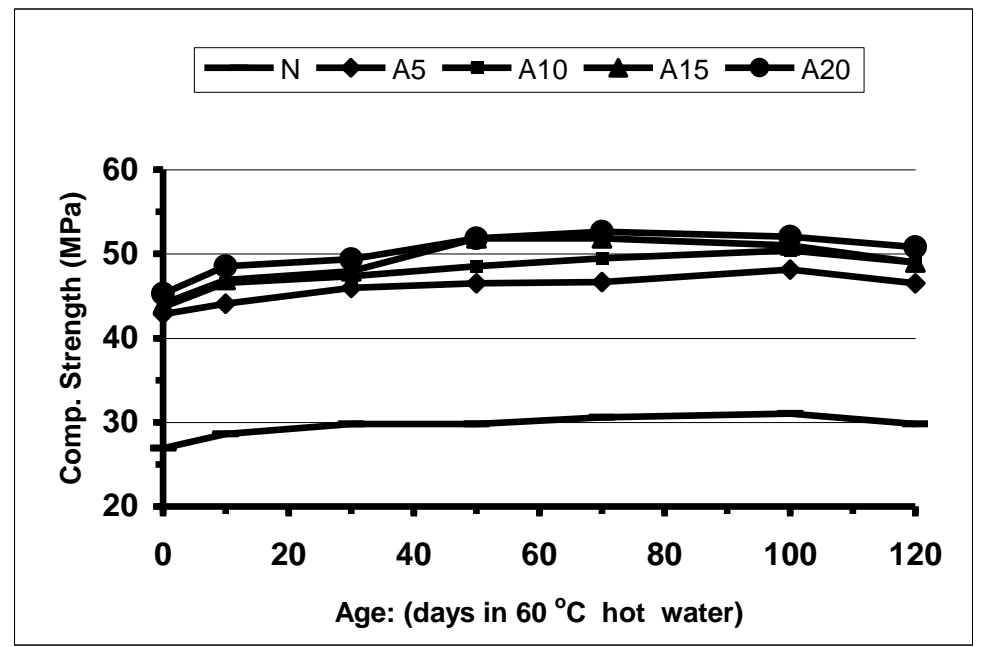

(b) S.F was used as an addition

Fig. 1 The effect of S.F content on the long-term compressive strength of mortar specimens

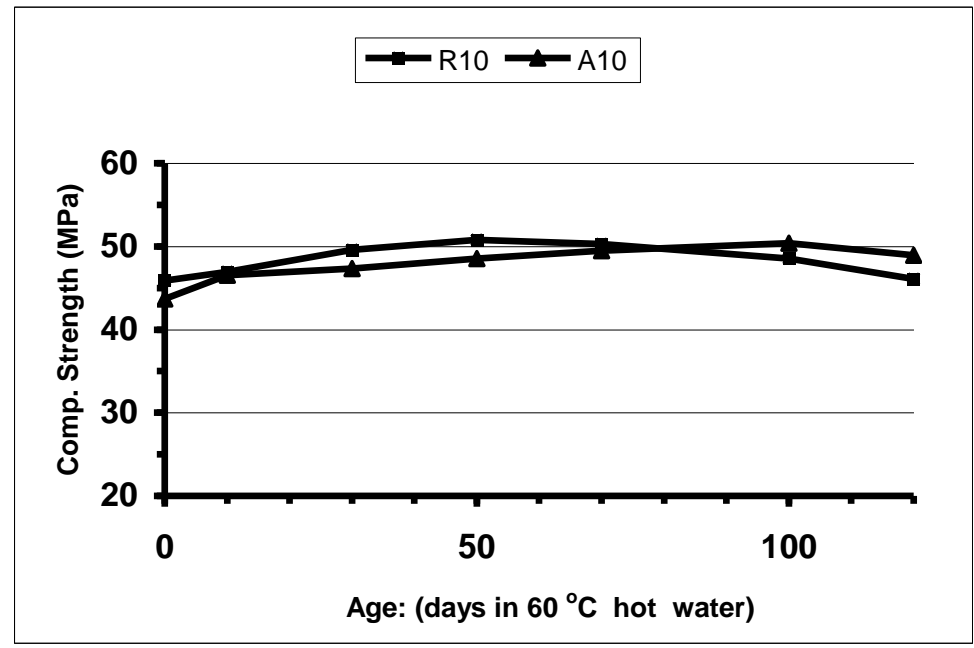

Fig. 2 Compressive strength of mortar specimens with $10 \%$ S.F as a replacement and as an addition 
H.S. Khalil, S.A. Ahmad, E.M. Abdin, S.E. Zakey, "Long -Term Mechanical Properties of High Strength ... "

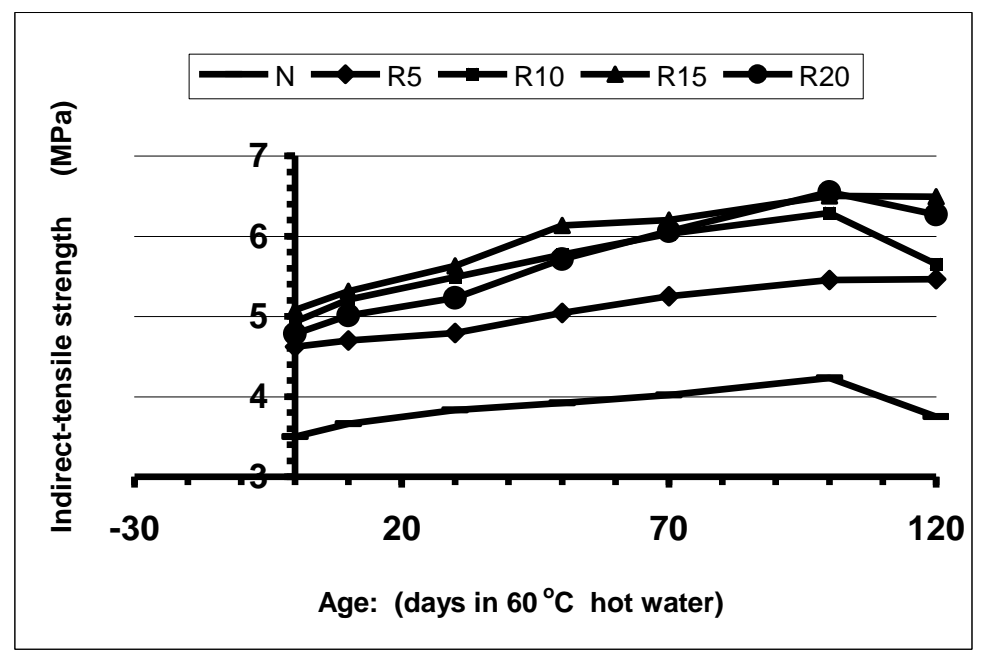

(a) S.F was used as a partial replacement

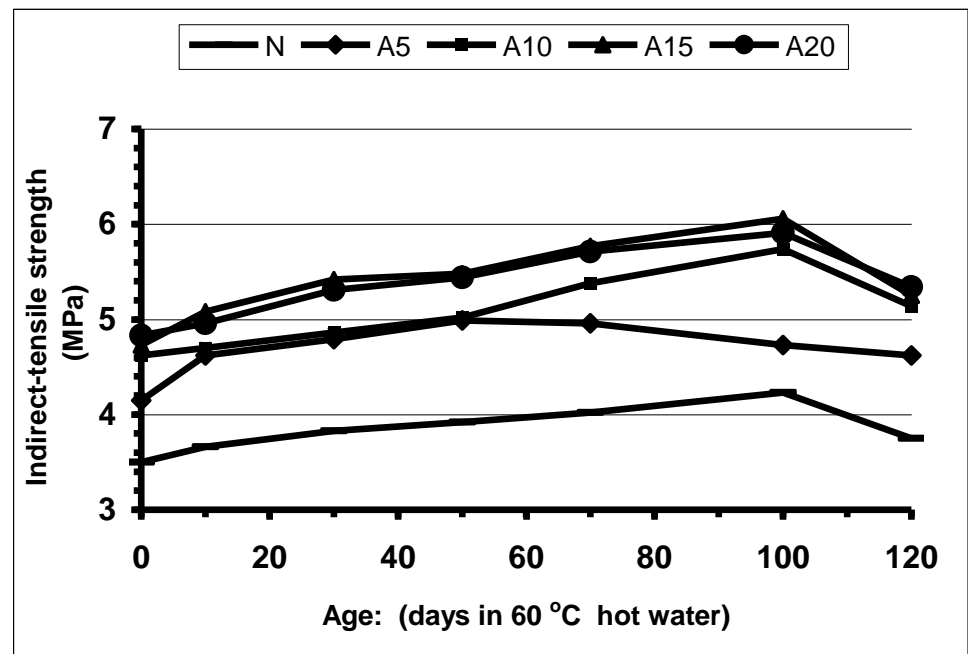

(b) S.F was used as an addition

Fig. 3 The effect of S.F content on the indirect tensile strength of the mortar specimens

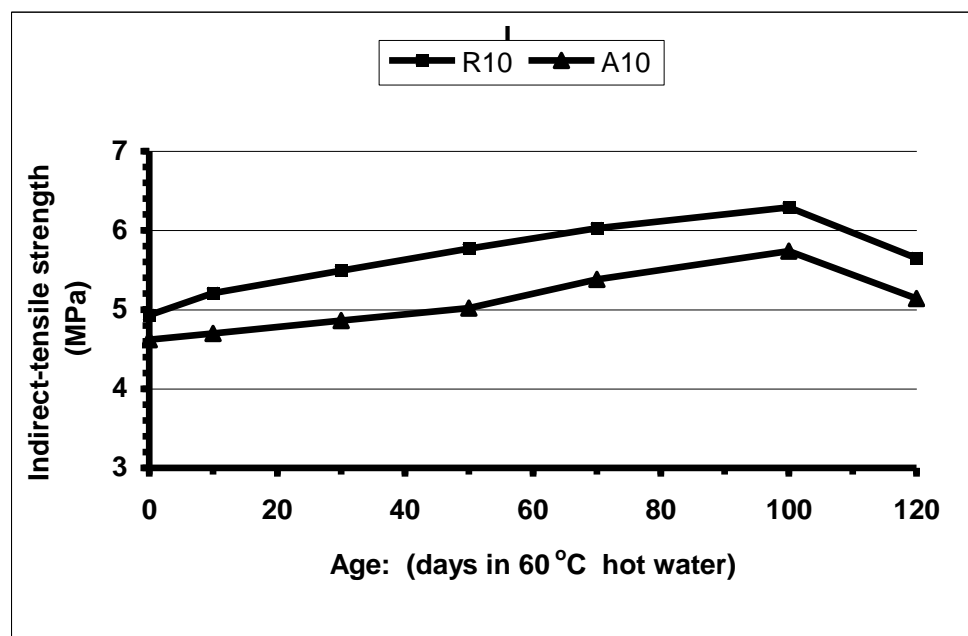

Fig. 4 Indirect tensile strength of mortar specimens with $10 \%$ S.F as a replacement and as an addition 
H.S. Khalil, S.A. Ahmad, E.M. Abdin, S.E. Zakey, "Long -Term Mechanical Properties of High Strength ... "

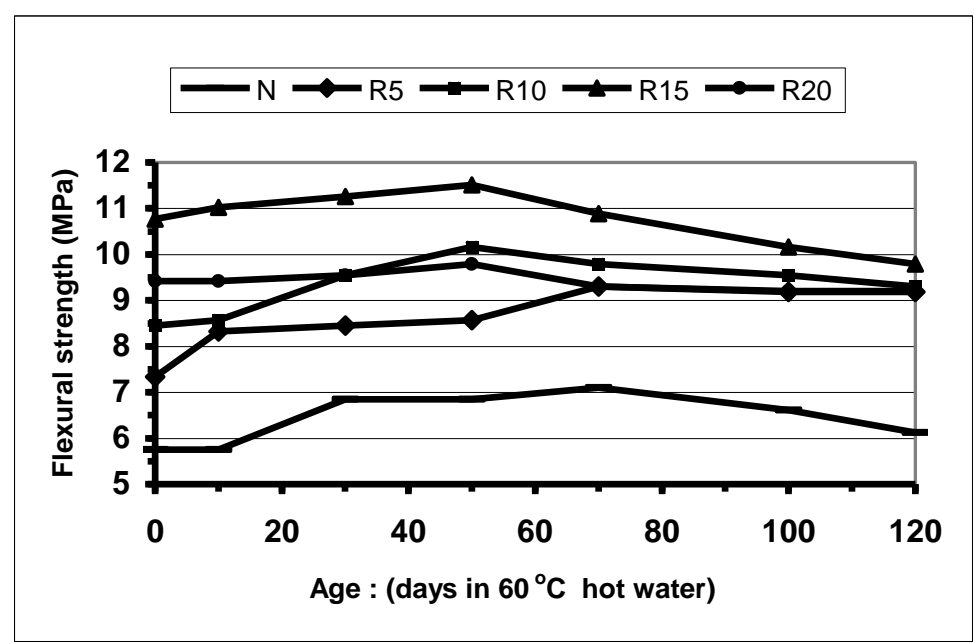

(a) S.F was used as a partial replacement

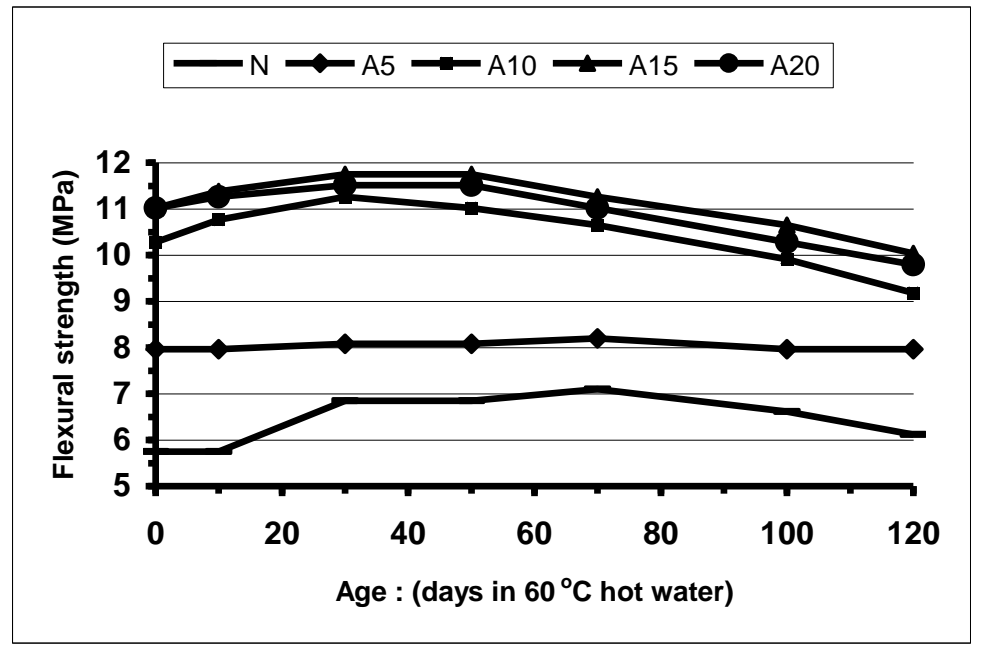

(b) S.F was used as an addition

Fig. 5 The effect of S.F on the flexural strength of the mortar specimens

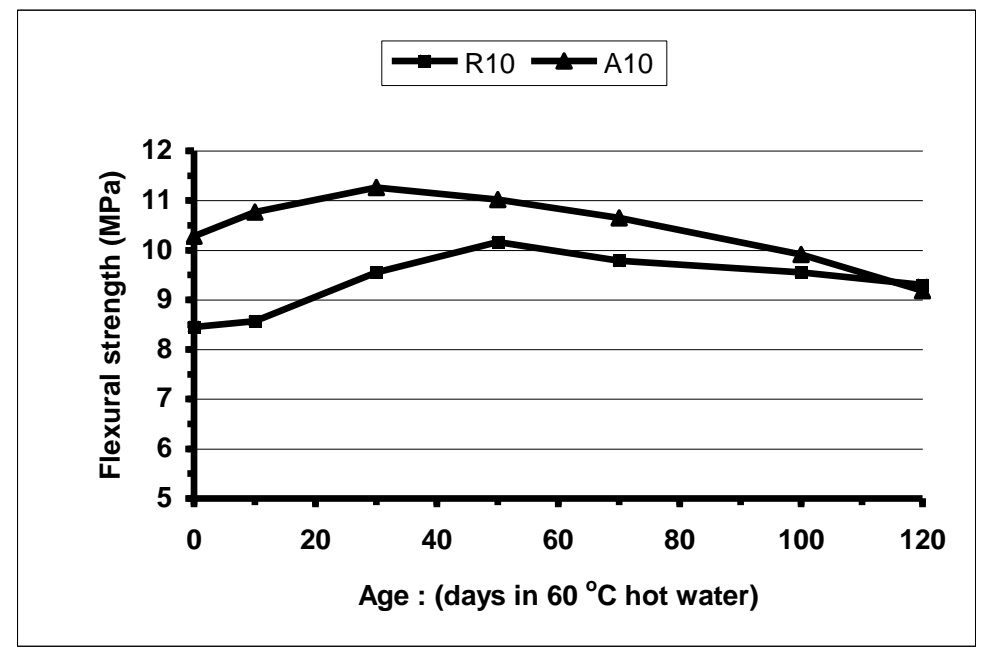

Fig. 6 Flexural strength of mortar specimens with 10\% S.F as a replacement and as an addition 